\title{
LibrAR: aplicativo de aprendizagem de libras usando realidade aumentada e realidade virtual em dispositivo móvel
}

\author{
Luan Ribeiro da Silva ${ }^{1}$, Dalton Solano dos Reis ${ }^{1}$, Mauricio Capobianco Lopes ${ }^{2}$ \\ ${ }^{1}$ Departamento de Sistemas e Computação - Universidade Regional de Blumenau (FURB) - \\ Rua Antônio da Veiga, 140 - CEP 89.030-903 - Blumenau, SC - Brasil \\ ${ }^{2}$ Programa de Pós-Graduação em Ensino de Ciências Naturais e Matemática - Universidade \\ Regional de Blumenau (FURB) - Blumenau, SC - Brasil \\ luan.ribeiro.svegmail.com, dalton@furb.br, mclopes@furb.br
}

\begin{abstract}
This article presents an application that uses Virtual Reality and Augmented Reality to aid the teaching of alphabet letters and numerals in LIBRAS. It has three modules: the first uses a 3D hand to display the letters and numerals in LIBRAS; the second and third are games for the user to train their knowledge in LIBRAS. During the tests with a group of students, only some initial difficulty was observed due to the lack of knowledge in the use of $R V$ and $R A$ technologies, but in the end, everyone was able to use the application and had fun with the tasks that were given to them. We concluded that the application has achieved its goals since the users showed great interest in the application to learn LIBRAS.
\end{abstract}

Resumo. Este artigo apresenta um aplicativo que utiliza Realidade Virtual (RV) e Realidade Aumentada (RA) para auxiliar no ensino das letras do alfabeto e algarismos numéricos em Libras. Ele tem três módulos: o primeiro usa uma mão 3D para mostrar as letras e algarismos numéricos em Libras; o segundo e o terceiro são jogos para que o usuário treine seus conhecimentos em Libras. Durante os testes com um grupo de estudantes, foi observada apenas uma dificuldade inicial em função do desconhecimento no uso das tecnologias de RV e RA, mas no fim todos conseguiram usar o aplicativo e se divertiram com as tarefas que lhes foram passadas. Conclui-se que o aplicativo alcançou seus objetivos pois os usuários demonstraram grande interesse no aplicativo para aprender Libras.

\section{Introdução}

Na década de 1850, um professor surdo francês chamado Ernest Huet chegou ao Brasil, trazendo com ele o alfabeto manual francês e alguns sinais. Nessa época, os surdos/mudos brasileiros ainda não possuíam um sistema de sinais próprio para se comunicar. Com a chegada da Língua de Sinais Francesa (LSF), foi criada a LIBRAS (Monteiro, 2006, p. 296). De acordo com Lopes (2013, p. 23), “[...] Libras é a língua utilizada como meio de comunicação pelas pessoas Surdas no Brasil. Trata-se de uma língua que não é universal, portanto, cada país possui a sua [...]". A LIBRAS é uma modalidade gestual-visual uma vez que, para comunicar-se através dela, são usados gestos e expressões faciais percebidos pela visão. (Revista Da Feneis, 1999, p. 16).

O uso de tecnologias digitais para o ensino de LIBRAS é um tema que desperta interesse e tem sido estudado com base em diferentes concepções e recursos (Klein, 2012; Reinoso; Almeida; Tavares, 2016; Rocha; Bittencourt; Brito, 2013; Bastos; Lins; Silva, 2016), entre eles a Realidade Virtual (Brega et al, 2013) e dispositivos móveis (Moura; Oliveira, 2014; Rocha et al, 2016). Segundo Forte e Kirner (2009, p. 1), "Pensar na adoção de 
VII Congresso Brasileiro de Informática na Educação (CBIE 2018)

Anais dos Workshops do VII Congresso Brasileiro de Informática na Educação (WCBIE 2018)

recursos tecnológicos como ferramentas facilitadoras no processo educacional pode ser encarado hoje como uma tarefa comum.". Nesse sentido, o presente artigo apresenta uma proposta baseada em Realidade Aumentada (RA), a qual possibilita inserir objetos virtuais no ambiente físico através de algum dispositivo tecnológico como, por exemplo, smartphones (Kirner, C.; Kirner, T., 2007 apud Forte; Kirner, 2009, p. 2). Além de RA utiliza-se também a Realidade Virtual (RV), que possui um conjunto de técnicas e ferramentas gráficas 3D que leva o usuário a um ambiente totalmente virtual gerado por um computador, podendo ainda realizar interações com esse ambiente, em tempo real, com quase nenhuma percepção que o ambiente onde está não é real (Leston, 1996, p. 12-13). Juntas, a RA e a RV apresentam boas possibilidades no desenvolvimento de aplicativos na educação oportunizando experiências e permitindo o desenvolvimento do educando no seu próprio ritmo (Pantelides, 1995 apud Forte; Kirner, 2009, p. 3).

Assim, o objetivo deste artigo é apresentar um aplicativo para dispositivo móvel para o aprendizado de LIBRAS combinando a RA e a RV. O aplicativo apresenta três módulos: o primeiro possibilita visualizar todas as letras do alfabeto e algarismos numéricos em uma mão virtual 3D; o segundo é um jogo usando RA para associar símbolos das letras e algarismos aos sinais; o terceiro é um jogo em óculos de RV para escolher o sinal correto para a letra ou algarismo numérico gerado aleatoriamente.

\section{Fundamentação}

Esta seção apresenta os fundamentos sobre LIBRAS e RA e RV utilizados para o desenvolvimento do aplicativo

\subsection{LIBRAS}

A LIBRAS é a língua oficial das pessoas surdas, conforme descrito em Brasil (2002)

Parágrafo único. Entende-se como Língua Brasileira de Sinais - Libras a forma de comunicação e expressão, em que o sistema linguístico de natureza visual-motora, com estrutura gramatical própria, constituem um sistema linguístico de transmissão de ideias e fatos, oriundos de comunidades de pessoas surdas do Brasil.

De acordo com Schlünzen, Benedetto e Santos (2012, p. 46), “As línguas de sinais são chamadas de gestual-visual porque o responsável para emitir a comunicação são as mãos por meio dos sinais, e o receptor são os olhos.”. A LIBRAS pode ser usada por pessoas surdas que entendem os sinais através da visão, por surdo-cegos que captam os sinais segurando a mão do emissor para poder entender e até por surdos que não possuem os braços fazendo os sinais com seus pés de forma adaptada (Schlünzen; Benedetto; Santos, 2012, p. 46).

Segundo Cechinel (2005, p. 32), “A Libras possui estrutura e gramática própria e status linguístico completo, possibilitando expressar não apenas conceitos concretos, mas também abstratos, assim como qualquer outro idioma.”. De acordo com Silva (2011, p. 2), cada sinal na língua de sinais pode ser composto de até cinco componentes chamados de parâmetros: configuração de mão: é a forma da estrutura da mão que deriva o sinal. A LIBRAS tem aproximadamente 70 configurações de mão; ponto de articulação: é a área do corpo na qual ou próxima da qual é realizado o sinal; movimento: é o movimento no espaço realizado pelas mãos durante o sinal; orientação: é a direção na qual a palma da mão aponta durante o sinal; expressão não-manuais: são expressões faciais e corporais realizados durante o sinal.

As Línguas de Sinais possuem uma estrutura frasal muito diferente das outras línguas. $\mathrm{Na}$ LIBRAS, para formar uma frase usa-se (objeto $\rightarrow$ verbo $\rightarrow$ sujeito) ou (objeto $\rightarrow$ sujeito $\rightarrow$ verbo), enquanto que na Língua Portuguesa a frase é formada por (sujeito $\rightarrow$ verbo $\rightarrow$ 
VII Congresso Brasileiro de Informática na Educação (CBIE 2018)

Anais dos Workshops do VII Congresso Brasileiro de Informática na Educação (WCBIE 2018)

objeto). Com isso, a frase "Eu vou para casa" falada no português ficaria "Casa vou eu" em LIBRAS (Schlünzen; Benedetto; Santos, 2012, p. 46). Conforme Schlünzen, Benedetto e Santos (2012, p. 46), "Em todas as línguas de sinais, inclusive na Libras, cada palavra é representada por um sinal, por isso é incorreto caracterizar os sinais da Libras como simples gestos ou mímicas, uma vez que se diferem por regras gramaticais específicas.”. Porém, cada letra e algarismo numérico também possui seu respectivo sinal em LIBRAS.

\subsection{Realidade Aumentada e Realidade Virtual}

Segundo Cardoso et al. (2007, p. 8)

Pode-se definir Realidade Aumentada - RA - como a amplificação da percepção sensorial por meio de recursos computacionais. Assim, associando dados computacionais ao mundo real, a RA permite uma interface mais natural com dados e imagens geradas por computador. Um sistema de RA deve prover ao usuário condições de interagir com estes dados de forma natural.

Com isso, RA é basicamente uma interação entre o mundo real e o mundo virtual, realizando isso através da geração de elementos virtuais no mundo real, fazendo o usuário acreditar que aquele elemento virtual faz parte realmente do mundo real. Como existe essa interação com o mundo real, a associação dos objetos virtuais gerados computacionalmente acaba ficando mais natural para os seres humanos, e esse é o grande objetivo da realidade aumentada (Cardoso et al., 2007, p. 8).

A RA representa, conforme Kirner, C.; Kirner, T. (2011, p. 11), "técnicas de interface computacional que levam em conta o espaço tridimensional. Nesse espaço, o usuário atua de forma multisensorial, explorando aspectos deste espaço por meio da visão, audição e tato.”. Os sistemas de RA podem ser classificados de quatro formas diferentes, que são: sistema de visão ótica direta, sistema de visão direta por vídeo, sistema de visão por vídeo baseado em monitor e sistema de visão ótica por projeção (Cardoso et al., 2007, p. 9-10).

Já a Realidade Virtual (RV), segundo Kirner e Siscoutto (2007, p. 7)

é uma "interface avançada do usuário" para acessar aplicações executadas no computador, propiciando a visualização, movimentação e interação do usuário, em tempo real, em ambientes tridimensionais gerados por um computador. O sentido da visão costuma ser preponderante em aplicações de realidade virtual, mas os outros sentidos, como tato, audição, etc. também podem ser usados para enriquecer a experiência do usuário.

Como mencionado, o usuário possui várias formas de interação com a RV. A mais simples que se pode considerar é a movimentação no espaço tridimensional, a qual pode acontecer através de um mouse $3 \mathrm{D}$, comandos de voz ou a própria movimentação do usuário detectada por um dispositivo de captura (Kirner; Siscoutto, 2007, p. 8). Agora quando se fala de interações mais complexas, como movimentação dos objetos virtuais em tempo real, necessita-se de dispositivos mais complexos, como um capacete de visualização, luvas eletrônicas, etc. Desta forma, o usuário terá impressão de estar no mundo real, porque estará manipulando, pegando e executando ações sobre os objetos virtuais em tempo real (Kirner; Siscoutto, 2007, p. 8).

Além dos dispositivos que o usuário irá usar quando houver essas interações mais complexas, o dispositivo que irá realizar todos os cálculos para renderizar esse ambiente tridimensional precisa obedecer a algumas taxas mínimas de renderização. Os atrasos admissíveis para visão e reações como tato, força e audição estão em torno de 100 milissegundos, isso significa que o dispositivo terá que rodar com taxas mínimas de 10 quadros por segundo (Kirner; Siscoutto, 2007, p. 8-9). Um sistema de RV possui alguns 
VII Congresso Brasileiro de Informática na Educação (CBIE 2018)

Anais dos Workshops do VII Congresso Brasileiro de Informática na Educação (WCBIE 2018)

módulos de processamento os quais, segundo Tori, Kirner e Siscoutto (2006, p. 15), podem ser resumidos em "leitura dos dados dos dispositivos de entrada, execução da simulação/animação e renderização sensorial. A renderização sensorial é considerada de forma ampla e engloba: renderização visual, auditiva e háptica.”.

De acordo com Tori, Kirner e Siscoutto (2006, p. 8), "Realidade Virtual pode ser classificada, em função do senso de presença do usuário, em imersiva ou não-imersiva". Pode-se chamar de RV imersiva quando o usuário é levado de forma inteira para o mundo virtual, através dos dispositivos multissensoriais que irão captar seus movimentos e reações para interagir com o mundo virtual, deixando-o completamente no mundo virtual, porém com impressão que está no mundo real. A RV não-imersiva é quando o usuário é levado parcialmente para o mundo virtual através de uma janela (monitor por exemplo), porém ele consegue perceber que está no mundo real (Tori; Kirner; Siscoutto, 2006, p. 8).

\section{LibrAR}

O cenário proposto para o LibrAR está dividido em três módulos. O primeiro módulo "Aprender os Sinais" tem o objetivo de mostrar para o usuário os sinais das letras do alfabeto e os algarismos numéricos a partir de uma mão 3D, realizando a animação necessária para o sinal. No segundo módulo "Jogo Associativo" o usuário tem o objetivo de associar o sinal na LIBRAS com o seu respectivo significado usando a RA. No terceiro módulo "Jogo de Raciocínio Rápido" o usuário precisa escolher o sinal correto para a letra ou algarismo numérico gerado aleatoriamente, usando a RV.

Para a implementação do aplicativo foi utilizado o motor de jogos Unity 3D na versão 2017.3.0f3 Personal. Para o uso da RA, foi utilizado o SDK Vuforia na versão 7.0.36. Já no uso da RV, foi utilizado o SDK Google VR para Unity na versão 1.120.0. O ambiente de desenvolvimento utilizado foi o Visual Studio Code com a linguagem de programação C\#. O aplicativo possui oito marcadores que são usados para o jogo de RA. Metade dos marcadores são responsáveis por exibir o sinal na LIBRAS, os quais são compostos por triângulos de quantidade e tamanhos aleatórios. A outra metade é responsável por exibir os significados dos respectivos sinais na LIBRAS. Os marcadores são compostos por arestas de tamanhos aleatórios. A Figura 1 mostra um exemplo dos marcadores.

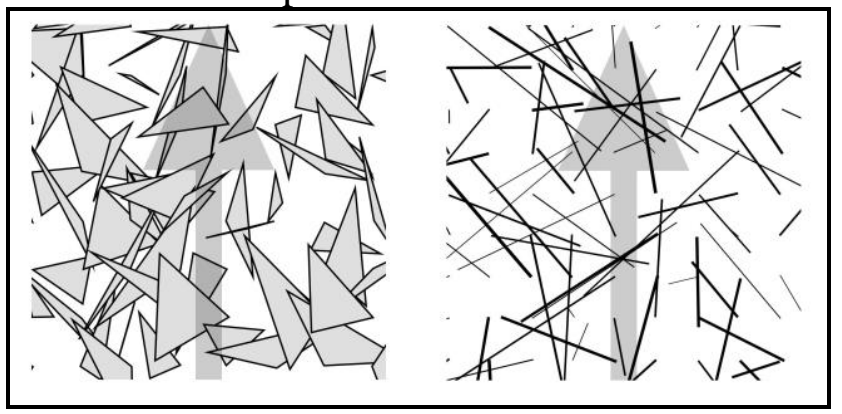

Figura 1 - Exemplo de marcadores do aplicativo

A Figura 2 mostra a tela inicial do aplicativo. 


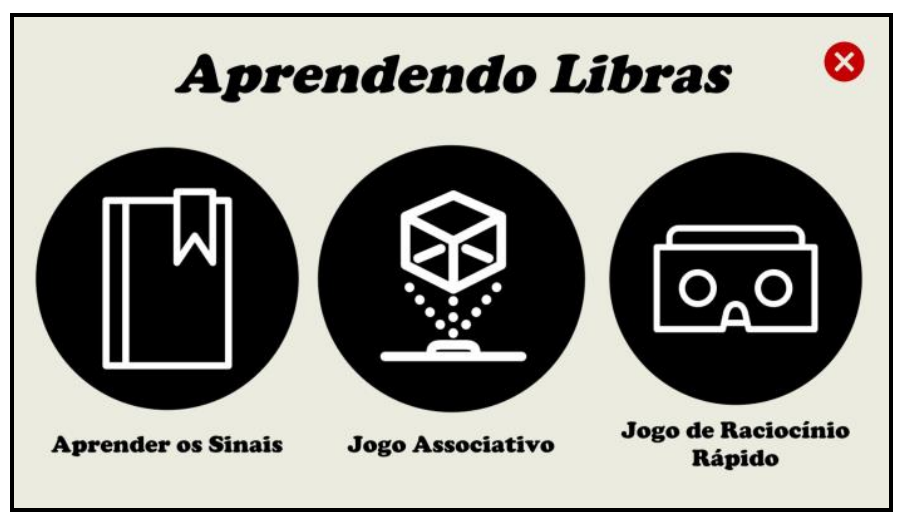

Figura 2 - Tela inicial do aplicativo

O módulo Aprender os Sinais tem o objetivo de mostrar ao usuário os sinais na LIBRAS das letras do alfabeto ou algarismos numéricos em ordem alfabética. Ao entrar no módulo, o usuário precisa escolher o conteúdo que ele irá visualizar, podendo escolher entre algarismos numéricos ou letras do alfabeto (Figura 3). Esta tela é comum a todos os módulos do aplicativo, portanto na explicação dos próximos módulos irá ser feito somente uma referência para a Figura 3.

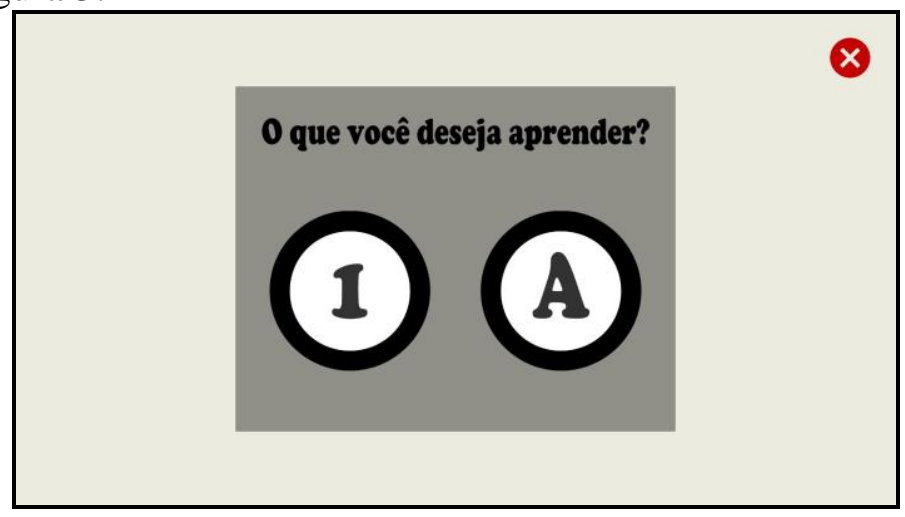

Figura 3 - Tela para o usuário escolher o conteúdo do módulo

O aplicativo desenvolvido possui uma mão 3D para representar os sinais na LIBRAS. Foi encontrado um molde gratuito com uma textura de uma mão real no site Cadnav, o qual disponibiliza modelos 3D de vários formatos, a maioria sendo de forma gratuita. Para conseguir fazer esta mão 3D representar um sinal na LIBRAS, foi necessário criar um esqueleto sobre ela e, para isto, foi usado o software Blender. Um esqueleto de uma mão 3D segue o mesmo princípio de uma mão real, com isto, foi criado um esqueleto com articulações muito semelhantes de uma mão real (Figura 4).

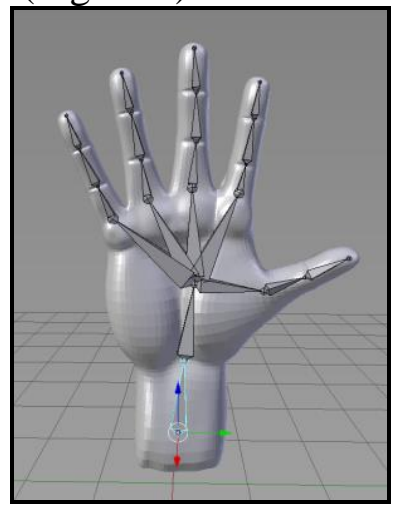

Figura 4 - Molde da mão 3D com esqueleto 
VII Congresso Brasileiro de Informática na Educação (CBIE 2018)

Anais dos Workshops do VII Congresso Brasileiro de Informática na Educação (WCBIE 2018)

Depois de montado o esqueleto no molde da mão 3D, foram criadas as animações dos sinais referentes às letras do alfabeto e aos algarismos numéricos. No Unity existem dois conceitos relacionados às animações, o Animation e o Animator Controller. O Animation trata de uma animação específica, por exemplo, a animação da letra A na LIBRAS. O Animator Controller refere-se à máquina de estados de animações do Unity, que é responsável por reproduzir cada animação em seu determinado fluxo. Para o aplicativo desenvolvido, foi criada uma animação para cada letra do alfabeto e algarismo numérico alterando-se as propriedades de rotação e posição de cada articulação do esqueleto da mão 3D.

A Figura 5 apresenta o módulo Aprender Sinais o qual se utiliza do modelo de mão 3D. No item 1 (Figura 5), é exibido o significado do sinal atual. O item 2 mostra a mão 3D realizando a animação do sinal na LIBRAS. Os itens 3 e 4 são botões para o usuário visualizar o sinal próximo/anterior na LIBRAS, respeitando a ordem alfabética. $\mathrm{O}$ item 5 é um botão com o objetivo de reexecutar a animação da mão 3D do sinal atual. O item 6 é um botão para o usuário voltar à tela para escolher um novo conteúdo para o módulo (Figura 3). O item 7 indica quando a animação do sinal foi finalizada e o item 8 é um botão para o usuário voltar ao menu inicial do aplicativo (Figura 2). O usuário pode rotacionar a mão 3D para poder visualizar todos os seus lados, para isto, é necessário pressionar o dedo na tela do dispositivo móvel e deslizá-lo para direita ou esquerda para realizar a rotação da mão 3D.

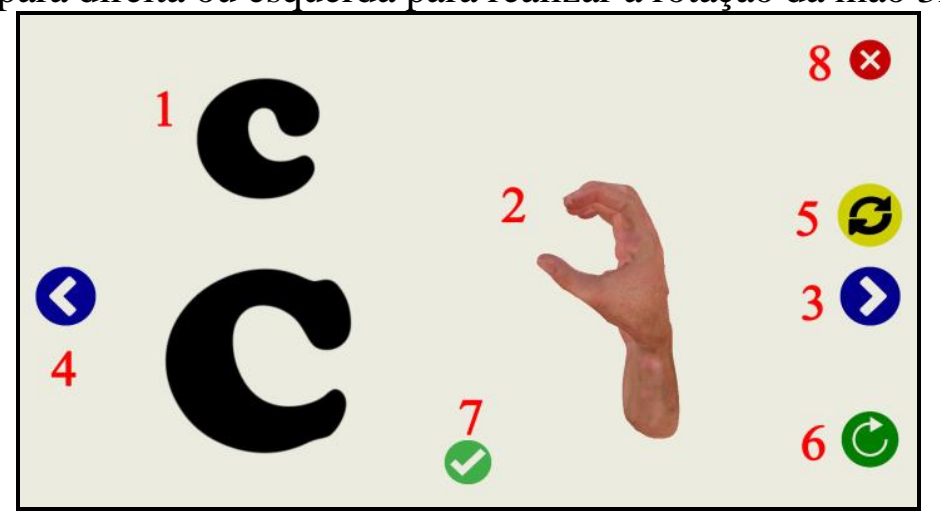

Figura 5 - Tela do módulo Aprender os Sinais

O segundo módulo, Jogo Associativo, disponibiliza ao usuário um jogo para treinar os seus conhecimentos na LIBRAS usando RA. O objetivo do jogo é associar o marcador do sinal na LIBRAS ao marcador que contenha o significado do sinal. Para o uso deste módulo é necessário imprimir os marcadores. É necessário também estar em um ambiente com uma boa iluminação e posicionar os marcadores em uma superfície plana.

Após escolher o conteúdo do módulo (Figura 3), o usuário visualiza a câmera do seu celular com algumas informações na tela. Em seguida, é necessário apontar a câmera para os marcadores para visualizar os sinais e os significados dos marcadores. No mundo real, o usuário deve encostar o marcador do sinal com seu respectivo significado. Esses passos devem ser seguidos até associar corretamente todos os marcadores ou até esgotar as suas tentativas. A Figura 6 mostra um exemplo deste módulo.

O item 1 (Figura 6) exibe ao usuário todos os sinais que ele precisa associar para ganhar o jogo. Neste mesmo item, é mostrado quais já foram associados de forma correta, por exemplo, o número dois é o único sinal que já foi associado, por isto está marcado com um sinal de correto ao lado dele. O item 2 exibe a quantidade de erros cometidos e o total de erros que podem acontecer durante o jogo. O item 3 é o marcador responsável por exibir o sinal na LIBRAS. O item 4 é referente ao marcador responsável por exibir o significado do sinal. Por fim, o item 5 é um botão para o usuário voltar à tela inicial do aplicativo (Figura 2). 
VII Congresso Brasileiro de Informática na Educação (CBIE 2018)

Anais dos Workshops do VII Congresso Brasileiro de Informática na Educação (WCBIE 2018)

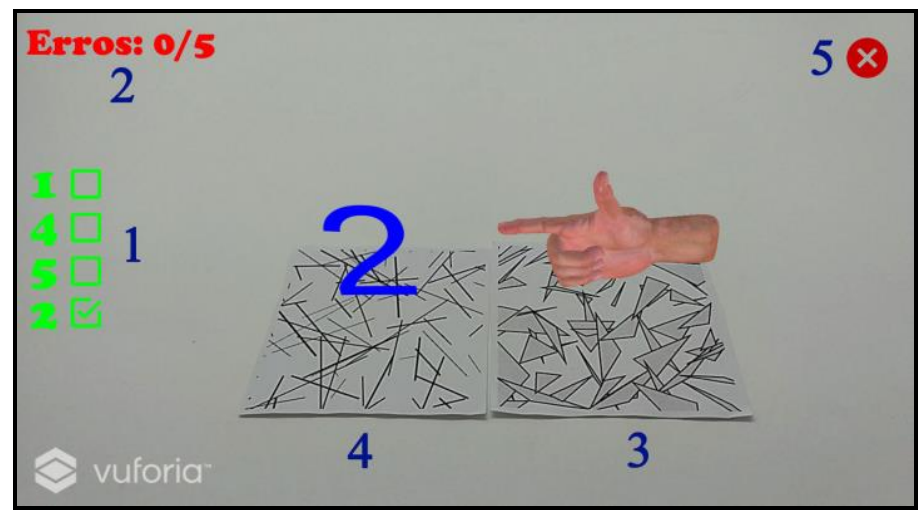

Figura 6 - Exemplo de tela do módulo Jogo Associativo

O módulo Jogo Raciocínio Rápido disponibiliza ao usuário uma forma mais interativa para treinar seus conhecimentos na LIBRAS usando RV. Para o uso deste módulo, é necessário ter algum modelo de óculos de RV (cardboard). Depois de entrar no módulo, é necessário colocar o celular no cardboard e escolher o conteúdo que irá visualizar (Figura 3). Em seguida, o usuário visualiza a tela da Figura 7. Neste módulo o objetivo é mexer a cabeça de uma forma que aponte para o sinal que o jogo está pedindo. O item 1 (Figura 7) indica qual sinal deve ser encontrado. $\mathrm{O}$ item 2 mostra os sinais disponíveis para serem escolhidos, sendo que só um deles representa o significado do item 1 . O item 3 é um círculo que indica para onde a cabeça está apontando no jogo. Para selecionar um dos sinais, basta manter o círculo em cima de uma das mãos 3D e esperar por aproximadamente dois segundos. Para indicar este tempo, o círculo fica totalmente branco. O item 4 mostra ao usuário o tempo que falta para o jogo acabar. $\mathrm{O}$ item 5 indica a quantidade de erros cometidos e a quantidade total. $\mathrm{O}$ item 6 é um botão que executa novamente a animação de todos os sinais para o usuário. $\mathrm{O}$ item 7 é um botão para o usuário voltar à tela para escolher um novo conteúdo para o módulo (Figura 3). O item 8 é um botão para o usuário voltar ao menu inicial do aplicativo (Figura 2).

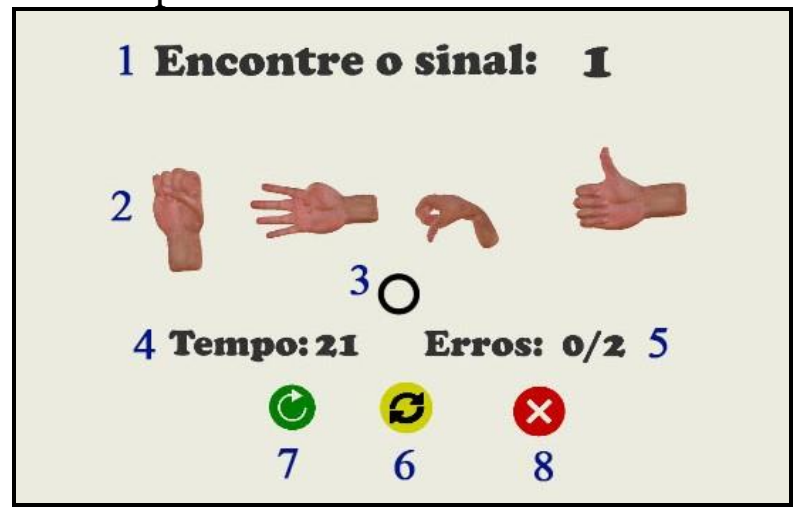

Figura 7 - Exemplo de tela do módulo Jogo Raciocínio Rápido

\section{ANÁLISE DOS RESULTADOS}

No decorrer do desenvolvimento do aplicativo foram realizadas duas reuniões com uma professora de LIBRAS. Na primeira reunião foi apresentada a animação dos sinais implementados e uma demonstração de como seriam os módulos. Nesta mesma reunião, a professora destacou alguns sinais que estavam sendo representados incorretamente. Após a análise, a professora gravou vídeos demonstrando a forma correta de representar os sinais para serem ajustados. 
Na segunda reunião, foi demonstrado o aplicativo completamente desenvolvido para a professora e uma estudante. No primeiro módulo, a professora destacou que não estava muito claro quando a animação do sinal executada pela mão 3D tinha finalizado ou não. Isso foi corrigido inserindo uma imagem para mostrar ao usuário que a animação estava em andamento e outra imagem indicando que foi finalizada. Os de mais módulos foram considerados corretos pela professora.

O experimento final do aplicativo foi realizado na Associação Blumenauense de Amigos dos Deficientes Auditivos (ABADA) com cinco estudantes, sendo todos deficientes auditivos e alguns com outras deficiências psicológicas. Antes dos alunos usarem o aplicativo, foi realizada uma explicação geral mostrando as funcionalidades de cada módulo. Após isto, eles foram divididos em três grupos, fornecendo-se dois tablets e um smartphone. Cada grupo tinha uma pessoa para auxiliar no uso do aplicativo. Para os dois primeiros módulos, a pessoa responsável passou as orientações para o grupo e, em seguida, deixou os estudantes livres para interagir com todas as funcionalidades de cada módulo. Para o terceiro módulo, foram passadas orientações individuais para cada estudante uma vez que havia apenas um óculos de RV para realizar os testes.

No primeiro módulo, foi observado que alguns alunos não ficaram muito interessados, pois todos já sabiam LIBRAS e este módulo tem o objetivo de mostrar as letras e os algarismos numéricos na LIBRAS. Entretanto, como era o primeiro módulo, no início pode-se observar alguma dificuldade no uso, porém, após alguns minutos, todos já estavam usando sozinhos. No segundo módulo, todos ficaram muito interessados por ser um jogo que usa realidade aumentada, o que era novidade para eles. Neste módulo, foi observado um pouco de dificuldade no começo na hora de associar os marcadores e segurar o celular ao mesmo tempo. Porém, depois de alguns minutos, todos já estavam usando sozinhos porque já estavam familiarizados com o uso do primeiro módulo. No terceiro módulo, o de Realidade Virtual, foram observadas duas dificuldades principais: inicialmente no primeiro momento em que se usava o óculos, pois os estudantes demoravam um pouco para entender que o movimento da cabeça era necessário para interagir com o aplicativo; também alunos que usavam óculos de grau, uma vez que era necessário tirá-lo para usar o óculos de RV o que acabou dificultando a identificação dos sinais no jogo.

No fim, todos ficaram livres para usar o aplicativo e pode-se observar que todos estavam conseguindo interagir com o aplicativo sozinhos. Nota-se que o padrão de botões utilizados tornou mais fácil o uso de todos os módulos, uma vez que depois dos alunos terem passado pelo primeiro módulo, eles já sabiam o que cada botão realizava no aplicativo, nos módulos seguintes. Por fim, analisou-se que o segundo módulo que usa RA ocasionou alguns travamentos em smartphones ou tablets que tenham hardware mais limitado.

\section{Conclusões}

Este artigo mostrou o desenvolvimento de um aplicativo para auxiliar no ensino de Libras. Os objetivos foram alcançados uma vez que os testes permitiram verificar que o uso da Realidade Aumentada e Virtual tornou o aplicativo divertido e envolvente. As ferramentas usadas mostraram-se adequadas para os fins que foram utilizadas. Os marcadores gerados pela ferramenta Brosvision foram muito bem detectados pelo Vuforia. O Blender facilitou muito a criação do esqueleto da mão sobre o molde. O Vuforia, usado para a Realidade Aumentada, tornou fácil a identificação dos marcadores e a interação entre eles. O Google VR, utilizado para a Realidade Virtual, facilitou a seleção dos objetos virtuais com o movimento da cabeça. O Unity possibilitou criar todas as animações dos sinais de Libras em cima da mão 3D. 
Por fim, este trabalho deixa uma contribuição social, pois o aplicativo desenvolvido pode ser usado para auxiliar no ensino dos sinais básicos de Libras por professores ou até mesmos pelos próprios estudantes. Os kits de marcadores e o cardboard usados para o desenvolvimento deste trabalho foram disponibilizados no Laboratório Interdisciplinar de Formação de educadores da Universidade Regional de Blumenau com o intuito de serem utilizados para este fim. Além disso, o aplicativo está disponível gratuitamente nas lojas de aplicativos para Android e iOS e pode ser utilizado por qualquer pessoa que se interessar.

\section{Referências}

Bastos, R. R.; Lins, L.; Silva, R. A. (2016) Aperfeiçoando o aprendizado da Libras utilizando elementos de Internet das Coisas. In: V Congresso Brasileiro de Informática na Educação. Anais dos Workshops... Uberlândia, 2016, p. 1364-1373.

Brasil. Lei $\mathrm{n}^{\circ}$ 10.436, de 24 de abril de 2002. Dispõe sobre a Língua Brasileira de Sinais Libras e dá outras providências. Brasília, 24 abr. 2002.

Brega J. R. F. et al. (2013) Sistema gerador de apoio a um dicionário temático visual-gestual baseado em realidade virtual. In: II Congresso Brasileiro de Informática na Educação. Anais dos Workshops... Campinas, 2013, p. 272-281.

Cardoso, A. et al. Tecnologias para o desenvolvimento de sistemas de realidade virtual e aumentada. Recife: Editora Universitária UFPE, 2007. 210 p.

Cechinel, L. Inclusão do aluno surdo no ensino superior: um estudo do uso de língua brasileira de sinais (LIBRAS) como meio de acesso ao conhecimento científico. 2005. $71 \mathrm{f}$. Dissertação (Mestrado) - Curso de Pós-Graduação Stricto Sensu, Centro de Educação de Ciências Humanas e da Comunicação, Universidade do Vale do Itajaí, Itajaí, 2005.

Forte, C. E.; Kirner, C. Usando realidade aumentada no desenvolvimento de ferramenta para aprendizagem de física e matemática. 2009. Disponível em: $<$ http://www.lbd.dcc.ufmg.br/colecoes/wrva/2009/008.pdf>. Acesso em 05 set. 2017.

Kirner, C.; Kirner, T. G. Evolução e Tendências da Realidade Virtual e da Realidade Aumentada. In: RIBEIRO, Marcos; ZORZAL, Ezequiel (Org.). Realidade Virtual e Aumentada: Aplicações e Tendências. Uberlândia: SBC - Sociedade Brasileira de Computação, 2011. Cap. 1.p. 10-25.

Kirner, C.; Siscoutto, R. Realidade Virtual e Aumentada: Conceitos, Projeto e Aplicações. Porto Alegre: Editora SBC, 2007. 292 p.

Klein, A. (2012) Prática bilíngue na educação infantil: Libras e português reflexões de uma prática. In: Congresso Brasileiro de Informática na Educação. Anais dos Workshops... Rio de Janeiro, 2012, p. 1-7.

Leston, J. Virtual reality: the IT perspective. ITNOW, Oxford, v. 38, p. 12-13, jun. 1996.

Lopes, R. A. Um olhar sobre o ensino de Libras na formação inicial em pedagogia: utopia ou realidade? 2013. 89 f. Dissertação (Mestrado em Psicologia) - Universidade Presbiteriana Mackenzie, São Paulo, 2013.

Monteiro, M. S. História dos movimentos dos surdos e o reconhecimento da Libras no Brasil. ETD - Educação Temática Digital. p. 295-305. 2006.

Moura, E. R. S.; Oliveira, E. H. T. (2014) Uma ferramenta colaborativa móvel para apoiar o processo de ensino-aprendizagem da LIBRAS e do Português para surdos. In: III Congresso Brasileiro de Informática na Educação. Anais dos Workshops... Dourados, 2014, p. 272-281. 
VII Congresso Brasileiro de Informática na Educação (CBIE 2018)

Anais dos Workshops do VII Congresso Brasileiro de Informática na Educação (WCBIE 2018)

Reinoso, L.; Almeida, R.; Tavares, O. (2016). Uma plataforma para construção de arquiteturas pedagógicas para a aprendizagem de LIBRAS. In: V Congresso Brasileiro de Informática na Educação. Anais dos Workshops... Uberlândia, 2016, p. 531-539.

Revista da Feneis. Rio de Janeiro: FA Editoração Eletrônica Ltda., Ano 1, n. 2, 1999. Disponível em: $<$ https://issuu.com/feneisbr/docs/revista_feneis_02>. Acesso em: 30 out. 2017.

Rocha, D. F. S.; Bittencourt, I. I.; Brito, P. (2013) AssistLibras: um assistente gráfico para construção de sinais 3D da LIBRAS. In: II Congresso Brasileiro de Informática na Educação. Anais dos Workshops... Campinas, 2013, p. 132-141.

Rocha, P. S. R. et al (2016); Gamificação: um aplicativo para o ensino da Língua Brasileira de Sinais. In: V Congresso Brasileiro de Informática na Educação. Anais dos Workshops... Uberlândia, 2016, p. 896-900.

Schlünzen, E.; Benedetto, L.; Santos, D. O que é Libras? Conteúdos e Didática de Libras. Presidente Prudente, v. 11, n. 24, 2012. p. 45-48.

Silva, G. M. Parâmetros da Libras. [2011?]. 10 p.

Tori, R.; Kirner, C.; Siscoutto, R. Fundamentos e tecnologia de realidade virtual e aumentada. Porto Alegre: Editora SBC, 2006. 412 p. 